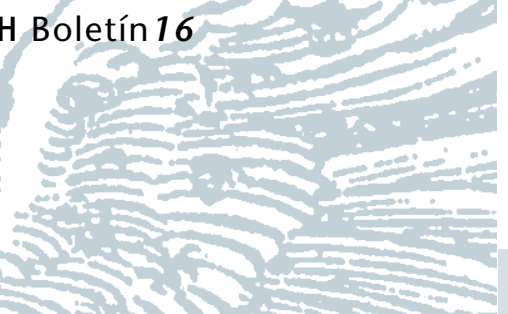

LA FORMACIÓN EN EL CAMPO DE LA GESTIÓN CULTURAL PARA UN CONCEPTO INTEGRAL DE PATRIMONIO. LA EXPERIENCIA DE LA FUNDACIÓN ORTEGA Y GASSET

Durante los últimos años, organismos relacionados con las industrias culturales han demostrado su preocupación por la formación y el reciclaje de profesionales que se adecúen a las nuevas demandas sociales en relación con lo consumos, necesariamente renovados, de lo que ha pasado a denominarse producto cultural. La Fundación José Ortega y Gasset ha organizado desde 1995 un Máster en Gestión Cultural: Patrimonio, Turismo, Ocio y Naturaleza, con la finalidad de crear a una nueva figura profesional capaz de gestionar recursos patrimoniales, dentro de una clara línea empresarial. Cuestiones de conservación y restauración del Patrimonio contaban ya con algunos cursos especializados; sin embargo, el capítulo relativo a su disfrute era la parte más descuidada. El curso ha tenido como objetivo prioritario replantear el papel de uso del Patrimonio en la sociedad actual, y añadir así un perfil profesional, tan nuevo como necesario, al estudio y difusión de los bienes culturales, en relación además con la renovación de la oferta turístico-cultural.

Al iniciar el diseño del curso, realizamos un estudio de todas las experiencias europeas en programas de formación generales o específicos de gestión cultural, con el fin de situar el Patrimonio en el contexto de cada una de las políticas culturales. Tratamos de definir un plan de formación para adaptar la peculiaridad del Patrimonio Español, en el que la relevancia de los bienes de interés cultural y natural transcendiera a su capacidad de testimoniar y documentar. Se trataba por tanto de definir muy bien cuál era el contexto, el criterio y la necesidad de formar un tipo específico de gestor cultural y con ello sacar al mundo de los recursos patrimoniales del campo único de la investigación, y desarrollar sus posibilidades a través de la gestión de distintas iniciativas culturales. Se trataba por tanto de profesionalizar a aquéllos que querían especializarse en el diseño de las expectativas del ocio y disfrute del $\mathrm{Pa}$ trimonio, y con ello, en las nuevas líneas de actividad económica en los sectores implicados, gracias al desarrollo de las capacidades organizativas y de planificación, en torno a los nuevos consumos culturales.

Es cada vez más necesario entender el ámbito patrimonial como un recurso activo de promoción, aún más en entornos como el español, que ofrecen una riqueza excepcional, sin duda no suficientemente aprovechada. Dicho patrimonio, entendido como soporte de actividades económicas, ha permanecido durante demasiado tiempo carente de especificidad en su gestión, de manera que parece razonable dirigir los intentos hacia la necesaria planificación de su uso social y de las nuevas tendencias reconocibles en los consumos socio-culturales.

La estructura y funcionamiento del curso confirman una voluntad de combinar de forma constante la investigación de carácter académico con un planteamiento ágil de los recursos y su planificación dentro de una clara línea empresarial.

Los objetivos principales del curso son:

- Integrar la profesionalidad dentro de los distintos sectores públicos y privados, académicos y técnicos, esto es, coordinar las expectativas de: posgraduados que deseen obtener una formación más empresarial, profesionales con experiencia en la industria turística que demandan conocimientos más académicos y profesionales del mundo de la administración que necesiten reciclar sus conocimientos en estos sectores.

- Proporcionar los instrumentos necesarios para que la gestión patrimonial añada a su dimensión cultural, la empresarial y la económica.

- Crear nuevos productos culturales que sean el resultado de la coordinación entre organismos y empresas que gestionan recursos patrimoniales. Se trata, en definitiva, de dar a conocer la herencia cultural a través de un producto de calidad.

A lo largo del programa se estudia el tejido empresarial, las consecuencias de los modelos económicos de las políticas culturales europeas, la cualificación de los recursos humanos en la empresa cultural y se diseñan proyectos empresariales en el marco de la industria cultural de carácter patrimonial, en un intento de canalizar las sinergias de todos los recursos: humanos, naturales, tecnológicos y financieros.
El programa académico garantiza además un período de prácticas personalizadas para cada alumno en prestigiosas instituciones de carácter público y privado, gracias a convenios de colaboración con nuestra Fundación, actividad ésta que permite el mantenimiento de relaciones estables con instituciones nacionales y extranjeras vinculadas a las gestión cultural. El resultado final es la elaboración por parte de cada alumno de un proyecto concreto de gestión de recursos patrimoniales.

Todos nuestros esfuerzos se esmeran en conseguir una aproximación multidisciplinaria a las políticas culturales relacionadas con el Patrimonio, cuya gestión pasa a formar parte de un sector de actividad enormemente ramificado, que comporta muchos saberes y metodologías, ante la amplia responsabilidad de mejorar las condiciones de esa función social.

Para más información al respecto pueden ponerse en contacto con el teléfono: 91 31044 12, exts. 250/25।

Olga Gómez Nuria Sanz Coordinadoras académicas

\section{JORNADAS DE MUSEOLOGÍA. "EL MUSEO, CENTRO DE DOCUMENTACIÓN"}

Durante los días 12, 13 y 14 de junio tuvieron lugar en el Museo Nacional de Antropología (Madrid) las Segundas Jornadas de Museología, organizadas por la Asociación Profesional de Museólogos de España (APME), bajo el título El Museo, Centro de Documentación.

La presentación estuvo a cargo de la Presidenta de APME, Angela García Blanco, el Director General de Bellas Artes y Bienes Culturales del Ministerio de Educación y Cultura, Benigno Pendas, y el Director General de Patrimonio Cultural de la Comunidad de Madrid, José Miguel Rueda. A continuación dieron comienzo las jornadas, estructuradas en nueve mesas redondas, integradas cada una por un ponente/moderador $y$ tres invitados pertenecientes a distintas comunidades autónomas, en las que mostraron sus experiencias dentro del ámbito de los museos:

I Documentación en los museos: una visión general. 
2 Colecciones en movimiento: ingresos, entradas temporales y préstamos.

3 Describiendo colecciones: ¿inventarios, catálogos, dossieres, etc...?

4 La colección en imágenes: del contacto de inventario al CD ROM.

5 Conservar para el futuro y guardar la información.

6 Entre el pasado y el futuro: los fondos documentales y los fondos administrativos.

7 La Biblioteca: un apoyo documental y científico del museo que se abre al exterior.

8 Aprendiendo a hablar un mismo idioma. Normalización de la información.

9 El difícil equilibrio entre la propiedad intelectual y el museo como servicio

Invitados por la organización de las jornadas a participar en la mesa redonda celebrada el día 14 bajo el título Aprendiendo a hablar un mismo idioma. Normalización de la Información, presentamos nuestra experiencia en el desarrollo del Tesauro de Patrimonio Histórico Andaluz.

Las mesas redondas se complementaron con demostraciones de programas informáticos documentales y sistemas de catalogación de fondos, presentados por distintas instituciones y firmas comerciales.

A lo largo de estas mesas redondas se intentó ver que los museos integran diversas funciones que se encuentran englobadas en la gestión de la documentación; por ello el museo debe considerarse en lo esencial como un centro de documentación.

Las conclusiones fueron presentadas por Andrés Carretero, miembro de la Comisión de Normalización Documental de Museos (Ministerio de Educación y Cultura), que tras reflexionar sobre el nombre de las jornadas, expuso las siguientes conclusiones:

- En las mesas redondas, se observó falta de unidad de criterios, centrándose cada una de ellas (en general) en experiencias personales, y prestándose mucha atención a las colecciones, lo que llevó a un estancamiento en el ámbito de la documentación.

- Propuso establecer Grupos de Trabajo que reglamenten la normativa, las pautas de actuación, la metodología de funcionamiento interno dentro de un museo, las recomendaciones estrictamente profesio- nales, etc...; todo ello creará un corpus de trabajo. En cuanto a la terminología (hay instituciones que están trabajando en ello), es necesaria la colaboración para evitar repetir esfuerzos.

- Planteó la disyuntiva sobre si había que tener técnicos especialistas en cada uno de los sistemas (Archiveros, Bibliotecarios, Documentalistas, tec...) que trabajasen con los Conservadores y Museólogos, o simplemente Conservadores y Museólogos con formación en Documentación o en otras especialidades afines. Para conseguir esta ultima opción se solicitó a la Asociación (APME) la organización de cursos específicos sobre planteamientos internos de los museos, entre los que destaca la documentación en museos.

- Por último, solicitó a los asistentes la aportación de otros temas específicos de museos para las próximas jornadas.

Acaban de ser publicadas las Actas de las I Jornadas de Museología, tituladas Formación y selección de profesionales de Museos, por lo que se espera publicar las Actas de las II Jornadas a la mayor brevedad posible.

Antonio Martín Pradas Centro de Documentación del IAPH

\section{SE CREA LA ASOCIACIÓN DE AMIGOS DEL MUSEO DE ARTES $Y$ COSTUMBRES POPULARES DE SEVILLA}

El pasado 10 de junio se constituyó la Asociación de Amigos del Museo de Artes y Costumbres Populares de Sevilla, con el objetivo de promover, estimular y apoyar cuantas acciones culturales, en los términos más amplios, tengan relación con la misión y actividad de este museo. La iniciativa partió de un grupo de antropólogos que colaboran desde hace años en esta institución, pensando que ésta puede ser una vía de actuación idónea para ampliar y hacer más efectivo el campo de cooperación. Experiencias similares se vienen llevando a cabo desde hace tiempo en otros museos españoles como el Museo Nacional del Prado, el Museo Nacional de Antropología, el Museo Nacional de Arte Romano de Mérida, el Museo Provincial de Bellas Artes de Sevilla y tantos otros que atestiguan la efectividad y el alto rendimiento alcanzados en estos cometidos.
Uno de sus fines primordiales es el acercamiento del museo a la sociedad, por lo que esta asociación no restringe su composición a los profesionales que de una forma más directa puedan estar vinculados a un museo etnográfico, sino que se abre a la participación de los más variados sectores sociales y profesionales, como demuestra la composición de la asamblea constitutiva, que cuenta con personalidades como: Andrés Carretero Pérez (Subdirector del Museo Nacional de Antropología), Manuel del Valle Arévalo (Presidente de la Fundación El Monte), José Ma Luzón Nogué (Catedrático de Universidad), Isidoro Moreno Navarro (Catedrático de Universidad), José Luis Ortiz Nuevo (Director de la Bienal de Flamenco), Salvador Rodríguez Becerra (Presidente de la Fundación Machado), Juan Manuel Suárez Japón (Catedrático de Universidad), Luis Uruñuela Fernández (Presidente de E.U.S.A.), entre otros.

En esta asamblea, formada por 43 socios fundadores, resultó elgida la junta directiva, con la siguiente composición:

Presidente: Antonio Rodríguez Almodovar (Catedrático de Instituto). Vicepresidente: José Manuel Padilla (librero). Secretaria: Esther Fernández de Paz (Profesora de Universidad). Vicesecretaria: Concepción Rioja López (Técnica de Patrimonio). Tesorera: Montserrat Barragán Jané (Antropóloga). Vocales: Concepción Alvarez Moro (Historiadora del Arte), Mercedes Betanzos Gil (Antropóloga), Román Fernández-Baca Casares (Director del IAPH), Mario Fuentes Aguilar (Fotógrafo), Macarena Hernández Ramírez (Antropóloga), Fernando Marmolejo Camargo (Orfebre), José Ma Morillas Alcázar (Profesor de Universidad) y Carlos Yañez Barnuevo (Director General de Asuntos Europeos).

De este modo se pretende aportar una ayuda que complemente los esfuerzos del propio museo por conseguir una institución más ágil en el cumplimiento de sus fines, especialmente los referidos a la divulgación del patrimonio cultural de los andaluces.

Entre sus proyectos más inmediatos figuran la edición de diverso material divulgativo de los fondos del Museo como el tríptico-guía para los visitantes, la guía del museo y los catálogos de diversas colecciones, como el de la colección de encajes y bordados de las hermanas Díaz-Velázquez; convocatoria de cursos, ciclos de conferencias y otras reuniones científicas que promuevan el conoci- 